\title{
Research on Buyback Contract of Supply Chain under the Newsvendor Model
}

\author{
Aimin $\mathrm{Li}^{\mathrm{a}}{ }^{\mathrm{a}}$, Shifang Yang ${ }^{\mathrm{b}}$, Zhiwei Zhou ${ }^{\mathrm{c}}$ \\ Department of Administrative Engineering, Zhengzhou University, Zhengzhou, China \\ a13733176771@139.com, ${ }^{b} 935120896 @ q q . c o m,{ }^{c} 15838116237 @ 139 . c o m$
}

Keywords: newsvendor model; buyback contract; supply chain

\begin{abstract}
The paper firstly reviewed the classic newsvendor model and expounded the establishment and solution to the model. Then the model of the supply chain system was established based on the classical newspaper model. Finally, based on the basic theory of repurchase contract, a repurchase agreement was established. The supply chain buyback contract under the newsvendor model can not only realize the coordination of supply chain, but also realize the distribution of profit in the supply chain.
\end{abstract}

\section{INTRODUCTION}

When the model was first proposed in 1956, it became the focus of the academic community, which was studied and analyzed by a large number of scholars or people in the economic field. As newsvendor model problems involved in the influence of many uncertain factors, people in order to study and quantify these factors, through a variety of mathematical methods to make the non-quantitative factors can maximize the quantitative expression, make it tend to be rational decisions. But these non-quantitative factors cannot be completely able to clear and quantitative, these are the bounded rationality of a newsvendor model.The problems and methods that are involved in limited rationality in newsvendor models have been developed in many ways. In terms of random factors, first of all, there are random requirements under uncertainty, inventory management, supply chain coordination, etc. When doing the limited rational decisions, people as far as possible through a specific calculation method to make optimal decisions, though not perfectly rational decisions, but it does to maximize profit nearly limited rational decision. In the newsvendor model, the randomness factor that the limited rational decision mainly faces is the demand and time. The newsvendor model is a typical stochastic demand model for the unit price, which aims to find the best order quantity of the product to maximize the expected gain or minimize the expected loss.

Yaxian Yin and Guangxing Wei ${ }^{[1]}$, on the basis of the newsvendor model, used a two-stage supply chain consisting of a supplier and a retailer to study the background and introduce fairness concerns into the study of repurchase contracts. They established a fair preference framework based on Nash's bargaining game, and studied the impact of fairness concerns on the repo contract by establishing utility model. Jiaguo Liu and Chong $\mathrm{Wu}^{[2]}$ analyzed the two-stage network effect of the supply chain of the newsvendor model, and established a distributed system, centralized system supplier and seller profit model based on the newspaper children model, and discuss how to eliminate the "double border" effect through a buyback contrac. Jinlaing Chen et $\mathrm{al}^{[3]}$ explored the newsvendor model and bayesian analysis model on the basis of asymmetric information under the supply chain system with updated demand forecast. Through the design subsidy contract to eliminate double marginalized due to low efficiency, he achieved supply chain coordination between upstream and downstream enterprises. Hongrui $\mathrm{Chu}^{[4]}$ studied the optimal order quantity in 3 situations by introducing the buyback and the shortage penalty under the framework of prospect theory.Yigang Zhang and Xiaowo Tang ${ }^{[5]}$ studied the influence of the fund income on the repurchase contract based on the newspaper child model in the case that the fund yield of the manufacturer is greater than that of the retailer's fund. Babich ${ }^{[6]}$ studied the problem of using buyback contracts to coordinate supply chains, assuming the demand information asymmetry between suppliers and retailers. Devangan ${ }^{[7]}$ used the cooperative game theory to study the supply chain repurchase contract which satisfies the individual rational constraint by using the cooperative game theory. Ruiz-Benite and Muriel ${ }^{[8]}$ introduced the return behavior of consumers into a supply chain system in a decentralized decision-making situatio.He studied the impact of the wholesale price contract and the repurchase contract on the coordination of supply chain, as well as the changes in the profit margin of the supply chain system when considering the return of the consumer. Feng yangang $^{[9]}$ introduced the stop behavior of consumers into the supply chain contract, and then studied the supply chain repurchase contract issue which considered the consumer's stop behavior.

The paper firstly reviewed the classic newsvendor model and expounded the establishment and solution of the model.Then the model of the supply chain system was established based on the classical newspaper model. Finally, based on the basic theory of repurchase contract, a repurchase agreement is established.

\section{CLASSIC NEWSVENDOR MODEL}

\subsection{Model description}

The newsvendor model says that newsvendors sell newspapers from wholesalers, and the demand for newspapers is random.If the demand is greater than the number of newspapers he takes from the wholesaler in 
the morning, he makes less money.If the demand is less than the number of newspapers he takes from the wholesaler in the morning, he can't sell the newspaper.Key decisions for newsvendors:How many newspapers should he buy when the daily demand is random?Set the newspaper to purchase price $b$, retail price $a$, return price $c$, natural hypothesis $a>b>c$. Try to plan the number of daily newspaper purchases to make the biggest income. How many newspapers will the newspaper boy buy every day?

\subsection{Model assumptions and analysis}

\subsubsection{Model assumptions}

(1) Suppose that the daily order price and the sale price of the newspaper are unchanged;

(2) Suppose that the demand for newspapers is not affected by other natural environments such as the weather;

(3) Suppose that the newsvendor can only buy newspapers from the newspaper once a day;

(4) Suppose that the newspaper doesn't sell the day, and nobody buys it the next day, it doesn't matter when the newspapers are sold on the same day.

(5) Suppose that the number of newspaper copies purchased by the newsvendor can be unlimited, in order to achieve the maximum profit for the purpose, the newspaper boy will not be able to purchase the newspaper from the newspaper except for the cost of the newspaper;

(6) Suppose that the "maximum profit" is understood to be the maximum profit per day for newsvendor.

\subsubsection{Model analysis}

If you buy too little newspaper every day, you don't sell enough, you make less money; If you buy too much, you can't sell it, you're going to lose money. Therefore, there is an optimal purchase volume, which makes the most benefit. So, the purchase quantity should be determined according to the demand. However, the daily demand is random, and the daily income is also random. Therefore, the objective function of the optimization problem should be the average daily income, which is equal to the expected daily income. Assuming that the newspaper boy has mastered the random order of demand through his own experience or other channels, the probability of a daily newspaper demand of $r$ copies per day in his sales is $f(r)(\mathrm{r}=0,1,2, \ldots)$.

\subsection{Model establishment}

The daily purchase quantity is $n$, because the quantity demanded $r$ is random, so the daily income of the newspaper boy is also random. Then, the daily average income of the long-term sale (month, year) is taken as the objective function of optimization model. From the point of view of the law of probability theory, this is equivalent to the expected daily income of newspaper children, short for average income. This kind of single period of buy to sell (newspapers, calendar, magazines and all kinds of seasonal goods and fashion), and beyond the purchase - goods sold cycle will, the problem is serious depreciation of the theory of storage were called to sell the newsvendor problem.

The inventory control strategy of such problems is the most significant target of profit expectation, and the purchase order quantity is determined once.The average income of a newsvendor who buys $n$ newspaper every day is $G(n)$. The newsvendor sells a copy earnings for $a-b$ and return a claim for $b-c$.

(1)If the demand is $r \leq n$, he sells $r$ copies and returns $n-r$ copies. Therefore, the profit of the newsvendor is $(a-b) r$, and the loss is $(b-c)(n-r)$.

(2)If the demand for the day is $r>n$, all the purchased newspapers $n$ are sold , so the profit for the newsvendor is $(a-b) r$. The probability of demand $r$ is $f(r)$, so we get:

$$
G(n)=\sum_{r-0}^{n}[(a-b) r-(b-c)(n-r)] f(r)+\sum_{r-n+1}^{\infty}(a-b) n f(r)
$$

The problem comes down to find $n$ makes $G(n)$ larges, when $f(r), a, b, c$ is known. So, $n$ is the optimal number of copies of the newspaper.

\subsection{Model solution}

Usually the quantity demanded $r$ and the purchase amount $n$ are quite large, so it can be regarded $r$ as a continuous variable for easy analysis and calculation. The probability $f(r)$ is converted to the probability density function $p(r)$, and the above equation becomes:

$$
G(n)=\int_{0}^{n}[(a-b) r-(b-c)(n-r)] p(r) d(r)+\int_{n}^{\infty}(a-b) n p(r) d r
$$

The reciprocal calculation of a is obtained:

$$
\begin{aligned}
& \frac{d G}{d n}=(a-b) n p(n)-\int_{0}^{n}(b-c) p(r) d r-(a-b) n p(n)+\int_{n}^{\infty}(a-b) p(r) d(r)(3) \\
& =-(b-c) \int_{0}^{n} p(r) d r+(a-b) \int_{n}^{\infty} p(r) d r \\
& \text { Let } \frac{d G}{d n}=0 \text {, then we get: }
\end{aligned}
$$

$$
\frac{\int_{0}^{n} p(r) d r}{\int_{n}^{\infty} p(r) d r}=\frac{a-b}{b-c}
$$

The average daily income $n$ of the newspaper children should be satisfied with the above formula. Because $\int_{0}^{\infty} p(r) d r=1$, therefore, the above expression can be expressed as:

$$
\int_{0}^{n} p(r) d r=\frac{a-b}{a-c}
$$

According to the graph of demand probability density function $p(r)$ can determine the purchase volume $n$.In the figure below, $p 1$ and $p 2$ are used to represent the area of two sections under the curve. 


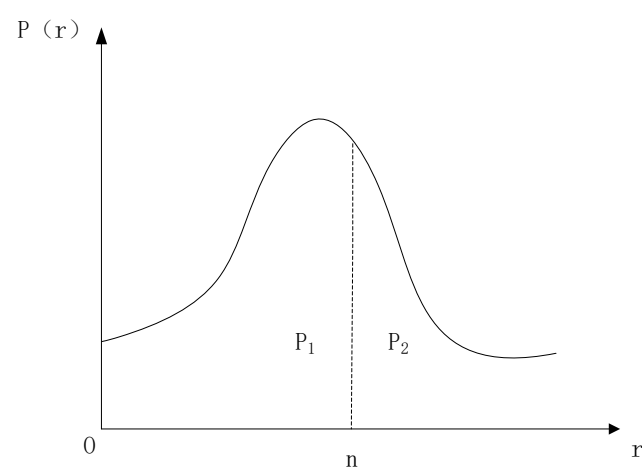

Fig 1

$$
\frac{p_{1}}{p_{2}}=\frac{a-b}{b-c}
$$

Because when you buy $n$ newspaper, $p_{1}=\int_{0}^{n} p(r) d r$ is the probability that the demand $r$ is not greater than $n$, the probability that you can't sell it. $p_{2}=\int_{n}^{\infty} p(r) d r$ is the probability that $r$ exceeds $n$, which is the probability of selling.

It is clear that the bigger the number of newspapers that newsvendors buy, the greater the number of newspapers that newsvendors buy when they have contracts with newspapers to make them bigger.

\section{THE BUY-BACK CONTRACT UNDER THE NEWSVENDOR MODEL}

\subsection{Basic model}

\subsubsection{Precondition}

In order to study convenience, suppose supply chain system is a secondary supply chain system with single supplier and single retailer.Among them, market demand is random and the retailer has only one opportunity to order before the selling season begins.Sellers face a stochastic market demand, and before the selling season according to the stipulations of contract to provide a quantity, if the actual demand is greater than the quantity, the seller will be the loss of opportunity cost, that is out of stock cost.If the actual demand is lower than your order, the seller will exist excessive holding costs.If the actual demand is lower than your order, the seller will exist excessive holding costs.Retailers face newsvendor model problem: retailers must in a single selling season with stochastic demand before choosing a order number.Assuming that both sides are risk neutral, that is to maximize their own profits as the goal of both parties.And both sides know all cost, parameters and rules.This model happen under two kinds of compliance mechanisms: voluntary compliance mechanisms and forced to follow.

Assume that the market demand is $D(D>0)$, expected demand expression in $\mu$, that is $\mu=E[D]$.The demand distribution function and the probability density function are respective $F(x), f(x) . F(x)$ is a strictly monotonic increment function, exist $F(0)=0, \bar{F}(x)=1-F(x)$.

Let's say the market retail price is $P$, The cost of the product of the supplier and the marginal cost of the retailer are respectively $C_{s}$ and $C_{r}$, The marginal cost of the retailer occurs when the retailer buys the goods. $g_{r}$ is the cost of loss of goods for retailers, $g_{s}$ is the cost of penalty for suppliers due to the shortage of the retailer,i in which $g=g_{s}+g_{r}$ is thetotal cost of punishment for a shortage of goods in the supply chain. At the end of the sales season, the retailer can obtain the residual value of the unsold goods per unit is $v$, in which $v<C$.

\subsubsection{Sequence of events}

First, the supplier provides a contract to the retailer, Retailers can choose to accept or reject it. Assuming the retailer accepts the contract, the retailer submits a number of $q$ orders to the supplier, then the supplier before the sales season production and transfer of products to retailers ,final transfer payment according to the two parties enter into a contract for transfer of the company. If retailers refused to contract, the contract ends.

\subsubsection{Profit function}

Assuming that the retailer's order quantity $q$, when the retailer's order quantity is $q$, expected profit with $\pi_{r}(q)$ said, expected sales with $S(q)$ said, expected surplus inventory with $I(q)$ said, expected sales loss with $L(q)$ said. Expected sales $S(q)$ is the minimum value for order and market demand, which means $S(q)=E[\min (q, D)]$, when $D>q$, mathematical expectation is $\int_{q}^{\infty} q \cdot f(x) d x=q \cdot(1-F(x))$, when $D<q$, mathematical expectation is $\int_{0}^{q} x \cdot f(x) d x$, then:

$$
\begin{aligned}
S(q) & =E[\min (q, D)]=q \cdot(1-F(x))+\int_{0}^{q} x \cdot f(x) d x \\
& =q-\int_{0}^{q} F(y) d y
\end{aligned}
$$

Expected surplus inventory $I(q)$ is the part when order quantity $q$ exceed market demand $D$, that is $I(q)=(q-D)^{+}$, then:

$$
\begin{aligned}
I(q) & =(q-D)^{+}=\int_{0}^{q}(q-x) \cdot f(x) d x \\
& =q \cdot F(q)-\int_{0}^{q} x \cdot f(x) d x \\
& =q-S(q)
\end{aligned}
$$

Expected sales loss $L(q)$ is the part when market demand $D$ exceed order quantity $q$,that is $L(q)=(D-q)^{+}$, then: 


$$
\begin{aligned}
L(q) & =(D-q)^{+}=\int_{q}^{\infty}(x-q) \cdot f(x) d x \\
& =\mu-\int_{0}^{q} x \cdot f(x) d x-q \cdot(1-F(q)) \\
& =\mu-S(q)
\end{aligned}
$$

Retailer's expected profits $\pi_{r}(q)$ then:

$$
\begin{aligned}
\pi_{r}(q) & =p \cdot S(q)+v \cdot I(q)-g_{r} \cdot L(q)-c_{r} \cdot q-T \\
& =\left(p-v+g_{r}\right) \cdot S(q)-\left(c_{r}-v\right) \cdot q-g_{r} \cdot \mu-T
\end{aligned}
$$

The profit function of the supplier:

$\pi_{s}(q)=-c_{s} \cdot q-g_{s} \cdot L(q)+T=g_{s} \cdot S(q)-c_{s} \cdot q-g_{s} \cdot \mu+T$

\section{Profit function of supply chain:}

For the simple calculation, let $c=c_{r}+c_{s}^{\prime} g=g_{r}+g_{s}$, then:

$$
\begin{aligned}
\Pi(q)= & \pi_{r}(q)+\pi_{s}(q)=\left(p-v+g_{r}+g_{s}\right) \cdot S(q)-\left(c_{r}+c_{s}-v\right) \cdot q-\mu \cdot\left(g_{r}+g_{s}\right) \\
& =(p-v+g) \cdot S(q)-(c-v) \cdot q-g \cdot \mu
\end{aligned}
$$

$q^{o}$ is the optimal order quantity for the supply chain, $q^{\circ}=\arg \max \Pi(q)$. Assume $\Pi\left(q^{\circ}\right)>0$, for $F(x)$ is a strictly augmented function, $\Pi(q)$ is the concave function, the optimal order quantity has a unique solution.

$q^{o}$ meet the conditions :

$$
S^{\prime}\left(q^{o}\right)=\bar{F}\left(q^{o}\right)=\frac{c-v}{p-v+g}
$$

$q_{r}^{*}$ is the optimal order for retailers, $q_{r}^{*}=\arg \max \pi_{r}(q)$. The distributor's order depends on transfer payments.

\subsection{The establishment of buyback contract under the newsvendor model}

Under the buyback contract, the retailer pays the supplier the price $w_{b}$ per unit, after the end of the sales season, the supplier pays the retailer $b$ each unit for the remaining inventory, then the retailer pays the transfer to the supplier:

$$
T_{b}\left(q, w_{b}, b\right)=w_{b} \cdot q-b \cdot I(q)=b \cdot S(q)+\left(w_{b}-b\right) \cdot q
$$

The above formula shows that the retailer paid to the supplier $w_{b}-b$ price per unit for all products ordered, at the same time, the retailer pays the supplier $b$ price per unit for all unsold products.

Because the retailer cannot profit from the remaining inventory, assumption $b \leq w_{b}$.Among them, an implicit assumption for suppliers to be able to accurately confirm the number of surplus products and the cost due to the clear to identify the remaining product quantity is not higher than the contract of additional benefits. Consider the retailer's order decision first, the expected profit of the retailer under the repurchase contract:

$$
\begin{gathered}
\pi_{r}\left(q, w_{b}, b\right)=\left(p-v+g_{r}-b\right) \cdot S(q)-\left(w_{b}-b+c_{r}-v\right) \cdot q-g_{r} \cdot \mu \\
\text { 令: } p-v+g_{r}-b=\lambda \cdot(p-v+g) \quad(\lambda>0) \\
w_{b}-b+c_{r}-v=\lambda \cdot(c-v)
\end{gathered}
$$

As $\left\{w_{b}, q\right\}$ is a pair of interacting parameters ,and they correspondent with each other, so adjust the relationship, and we can get one $\lambda$ meets the above formula.

Plug it in above formula:

$$
\begin{aligned}
& \pi_{r}\left(q, w_{b}, b\right)=\lambda \cdot(p-v+g) \cdot S(q)-\lambda \cdot(c-v) \cdot q-g_{r} \cdot \mu \\
= & \lambda \cdot \prod(q)+\mu \cdot\left(\lambda \cdot g-g_{r}\right)
\end{aligned}
$$

And with $\lambda$ is to make the first order derivative condition is the same, that is $q_{r}^{*}=q^{o}$.

Then consider supplier's decision, at the supplier's profit is:

$$
\begin{aligned}
\pi_{s}\left(q, w_{b}, b\right) & =\prod(q)-\pi_{r}\left(q, w_{b}, b\right) \\
& =(1-\lambda) \cdot \prod(q)-\mu \cdot\left(\lambda \cdot g_{s}-(1-\lambda) \cdot g_{r}\right)
\end{aligned}
$$

As a result, the buyback contract can make the suppliers to achieve coordination. Above all, we can get:provided $\lambda \leq 1$, in the case of voluntary compliance, repurchase contract achieve coordination is possible, but the best solution is not the only one Nash equilibrium, which depends on the values of $\left\{w_{b}, b\right\}$.

At the same time, voluntarily comply with the contract actually enhance the robustness of the supply chain. Assuming that retailers choose the order $q>q^{o}$ of irrational decision-making. Because the supplier can choose to deliver goods less than the number of retailers, therefore, the supplier will select the optimal order of delivery $q^{o}$ to correct the wrong decision made by the retailer. However, because retailers can refuse to buy more than they can order, suppliers can't make the wrong decisions about retailers when their orders are less than optimal $q^{o}$.

Next, we consider the profit distribution of suppliers and retailers.The profit of the retailer is the increment function of $\lambda$, so it plays a role in coordinating profit distribution of supply chain.

If the retailer gets the full profit of the supply chain: then:

$$
\pi_{r}\left(q^{0}, w_{b}, b\right)=\prod\left(q^{0}\right)
$$

There is: 


$$
\lambda=\frac{\prod\left(q^{o}\right)+\mu g_{r}}{\prod\left(q^{o}\right)+\mu g} \leq 1
$$

At the same time, if the supplier obtains the entire profit of the supply chain:

then:

$$
\pi_{s}\left(q^{0}, w_{b}, b\right)=\prod\left(q^{0}\right)
$$

There is:

$$
\lambda=\frac{\mu \cdot g_{r}}{\prod\left(q^{o}\right)+\mu \cdot g} \geq 0
$$

Therefore, including $\lambda=0$ and $\lambda=1$,each profit distribution scheme under the buyback contract is feasible. Supply chain coordination needs to adjust the wholesale price and repurchase price to determine the parameters $\lambda$,this will achieve the coordination of the supply chain.

Because the parameters $\lambda$ are not real in the buyback contract, although the profit distribution in the supply chain can be explained by $\lambda$ roughly, only when $g_{r}=g_{s}=0, \lambda$ becomes the accurate profit allocation parameter under the buyback contract.

Under the buyback contract, when the ordered quantity is $q^{o}$, the profit of the supplier is :

$\pi_{s}\left(q^{o}, w_{b}, b\right)=g_{s} \cdot S\left(q^{o}\right)-c_{s} \cdot q^{o}-g_{s} \cdot \mu+b \cdot S\left(q^{o}\right)+\left(w_{b}-b\right) \cdot q^{o}$

Make

$$
\frac{\partial \pi_{s}\left(q^{o}, w_{b}, b\right)}{\partial q^{o}}=\left(b+g_{s}\right) \cdot S^{\prime}\left(q^{o}\right)-c_{s}+w_{b}-b=0
$$

, plug in $S^{\prime}\left(q^{o}\right)=\frac{c-v}{p-v+g}$, find the wholesale price

when the quantity is optimal:

\subsection{Analysis of Result}

$$
w_{b}(b)=b+c_{s}-(c-v) \cdot\left(\frac{b+g_{s}}{p-v+g}\right)
$$

After conclusion of the buyback contract, the overall profit of the supply chain reaches the state of integration mode. With the increase of ratio of profit distribution, sellers of falling profits, profit increasing and suppliers. But both the total profit is always higher than the sum of the profits of the dispersed mode. Overall, wholesale repurchase contract when using the contract by the wholesale price is not the wholesale price is low, and increase the order quantity, so that the total supply chain profit increased, and reduced the stock losses, and better meet customer needs. In the retail price is the supplier in the determination of the given first, and in the model is always a constant value, so the buyback model must ensure that the supplier to the retailer's retail price, the control of the operations of the enterprise in aspects and so on for the establishment of the brand has a good advantage.

\section{CONCLUSIONS}

The reason for the supply chain coordination is that the supplier also assumes a certain risk market risk, therefore, the supplier must also obtain a certain profit. For the retailer, it can return the unsold goods to the supplier and reduce the risk, So will save a part of profits to suppliers. To sum up,under the newsvendor model, supply chain under the buyback contract can achieve supply chain coordination, to achieve profits in asked subjects to the arbitrary allocation of supply chain.

\section{REFERENCES}

[1] Yaxian Yi, Guangxing Wei. The supply chain coordination model based on the repurchase contract is based on the equity preference[J]. Economic Mathematics,2013,30(4):45-48.

[2] Jiaguo Liu, Chong Wu. A two-stage supply chain repurchase contract coordination study based on the newsvendor model [J]. Management Science in China, 2010,18(4):73-78.

[3] Jinliang Chen, Hua Song, Yu Xu. Under asymmetric information, supply chain contract coordination research with demand forecasting and updating is given[J]. Management Science in China,2010(2):84 -89.

[4] Hongrui Qi, Lun Ran. newsvendor problem based on prospect theory: consider buybacks and out-of-stock penalties [J]. Journal of management science,2015,18(12):47-56.

[5] Yigang Zhang, Xiaowo Tang. Consider the supply chain repurchase contract in the case of capital gain [J],2012,26(1):137-142.

[6] Babich V., Li H., Ritchken P.,et al. Contracting with Asymmetric Demand Information in Supply Chains[J]. European Journal of Operational Research, 2012, 217(2): 333-341.

[7] Devangan L., Amit R. K., Mehta P.,et al. Individually Rational buyback contracts with Inventory Level Dependent Demand[J]. International Journal of Production Economics, 2013,142(2) :381-387.

[8] Ruiz-Benitez R,Muriel A. Consumer Returns in a Decentralized Supply Chain[J].International Journal of Production Economics,2014,147( 1) :573-592.

[9] Yangang Feng, Li jian, Wu jun. Consider the supply chain repurchase contract study of consumer stop behavior [J]. Logistics and Operations (Bräagement, 2014,26 (8):181-187. 